\title{
Creatividad e Inteligencia Emocional. (Como desarrollar la competencia emocional, en Educación Infantil, a través de la expresión lingüística y corporal)
}

\author{
Purificación CRUZ CruZ \\ Universidad de Castilla la Mancha. \\ purificacion.cruz@uclm.es
}

\begin{abstract}
Resumen:
Es importante poner al alcance de los alumnos de Educación Infantil, ya que es la etapa de la máxima expresividad, todos los tipos de lenguaje que les sirvan para expresar su mundo emocional: el lenguaje del cuerpo, el lenguaje musical, el lenguaje plástico, el lenguaje verbal y no verbal y el juego simbólico. Por eso, los docentes deben aprender a gestionar en sus aulas las emociones y habilidades sociales de sus alumnos. Desarrollando su Inteligencia Emocional de forma creativa, lúdica y divertida.
\end{abstract}

Palabras clave: inteligencia emocional; expresividad; juego teatral; infantil.

Creativity and Emotional Intelligence.

(How to develop emotional competence, in Preschool, through linguistic expression and body language).

\begin{abstract}
:
It is important to put into reach amongst the pupils of Preschool all the different types of language which will serve them to express their emotional world, since it is the stage of maximum expressivity: body language, musical language, plastic language, verbal and non-verbal language and symbolic game. For this reason, teachers must learn to manage the emotions and social abilities of their pupils in their classrooms developing their Emotional Intelligence in a creative, playful and entertaining manner.
\end{abstract}

Key Words: Emotional intelligence; expressivity; theatrical game; preschool.

Referencia normalizada:

Cruz Cruz, P. (2014): Creatividad e Inteligencia Emocional. (Cómo desarrollar la competencia emocional, en Educación Infantil, a través de la expresión lingüística y corporal). Historia y Comunicación Social. Vol. 19. Núm. Especial Enero. Págs. 107-118.

Sumario: 1. Introducción. 2. Competencias y habilidades propias de la Inteligencia Emocional. 2.1. Relación entre Competencia Emocional y Juego Teatral. 3. Currículo y dramatización. 4. Cómo desarrollar la Inteligencia Emocional. 4.1. A través de la lectura y representación de cuentos. 4.2. A través de la Expresión dramática y corporal. 4.2. Enfoque metodológico. 4.3. Campos de actuación. 5. Conclusión. 


\section{Introducción}

Daniel Góleman define Inteligencia Emocional como la capacidad de establecer contacto con los propios sentimientos, discernir entre ellos y aprovechar este conocimiento para orientar nuestra conducta, y la capacidad de discernir y responder adecuadamente a los estados de ánimo, temperamento, motivaciones y deseos de los demás. (Góleman, 1996).

El desarrollo de la Inteligencia Emocional, debe ser unos de los objetivos prioritarios a trabajar en la etapa de la Educación Infantil, ya que el niño inicia su escolarización con un desarrollo madurativo cargado de energía emocional, necesidad de comunicar sus sentimientos y emociones y falta de destreza en la utilización de los cauces adecuados de comunicación de dichas sensaciones y necesidades efectivas. Es el momento en el que el niño puede reír o llorar, pedir o exigir, aceptar o negar de forma exagerada.

Se trata de un educando que todavía tiene su sistema nervioso en formación, su psiquismo en construcción y su personalidad en elaboración. Desde todos los puntos de vista. El potencial de accesibilidad que posee el niño de Educación Infantil debe ser aprovechado para enriquecer al máximo sus capacidades y competencias. Esta necesidad de comunicación y de aprendizaje comunicativo le permitirá adaptarse al nuevo ambiente escolar, social y familiar al que se incorpora.

Es importante poner al alcance de los alumnos todos los tipos de lenguaje que les sirvan para expresar su mundo emocional: El lenguaje del cuerpo, el lenguaje musical, el lenguaje plástico, el lenguaje verbal, el lenguaje no verbal y el juego simbólico. Y, por tanto, un buen camino para el descubrimiento de las emociones es a través de la expresión lingüística y de la expresión corporal, con el juego y la experimentación como medio de enlace en las actividades desarrolladas en el aula.

Por ello, es fundamental que los maestros y maestras que trabajan en el ciclo educativo de Educación Infantil, sepan gestionar en sus aulas lo emocional. Se debe intentar conectar con los sentimientos, los deseos, las vivencias, los conflictos, las necesidades, los intereses de los alumnos y alumnas, y establecer complicidad con ellos y ellas. Así se podrá ayudar a construir una estructura personal adecuada y a dotarles de capacidades para relacionarse socialmente.

\section{Competencias y habilidades propias de la Inteligencia Emocional}

Begoña Ibarrola (2009), en su publicación "Crecer en emociones", nos enumera cada una de las competencias que debemos trabajar en las aulas e incluso en el entorno familiar para conseguir que nuestros alumnos y nuestros hijos sean competentes emocionalmente. Como se puede apreciar, la autora establece un proceso de aprendizaje que parte de las emociones del sujeto para llegar a conocer los senti- 
mientos de los demás y conseguir, por último, un acercamiento, empatía y destreza social. El establecimiento de estas categorías o competencias a trabajar, quedarían establecidas de la siguiente forma:

- Conocimiento de las propias emociones (Autoconciencia): Capacidad de reconocer un sentimiento en el mismo momento en el que aparece, lo que constituye la piedra angular de la I. Emocional ( Ibarrola, 2005) ${ }^{1}$. Para conseguirlo, el alumno debe aprender a ser consciente de sus propias emociones, identificarlas correctamente y ponerlas nombre, y por último comunicarlas de forma verbal y no verbal. El docente debe jugar con el alumno para que en distintas situaciones se hable o se representen emociones como la alegría, tristeza, enfado, frustración, etc., ya que ello incrementa nuestra capacidad de control de las situaciones, la reparación de un estado de ánimo alterado y la búsqueda de soluciones a los problemas.

- Capacidad de regular las emociones (Autocontrol): Definida por Ibarrola como la capacidad que nos permite controlar la expresión de nuestros sentimientos y emociones, y adecuarlos al momento y al lugar. Esto se conseguirá si trabajamos estrategias de autocontrol emocional, expresión adecuada de emociones y la tolerancia a la frustración. No consiste en anular o eliminar las emociones sino enseñar al niño a buscar el camino adecuado de expresión de esa emoción para que no se haga daño a sí mismo ni a los demás. El objetivo principal no es reprimirlas, sino comprenderlas mejor y expresarlas de forma adecuada. De igual modo, los niños necesitan ayuda y práctica para construir su tolerancia a la frustración; debiendo aprender formas positivas de hacer frente a esos sentimientos.

- Capacidad de motivarse a sí mismo (Automotivación): Estableciendo Ibarrola un conjunto de habilidades y características relacionadas con la autogestión emocional. Destacando la autoestima, automotivación y actitud positiva y optimista.

- Reconocimiento de las emociones ajenas (empatía): Entendiendo por empatía la capacidad de entender lo que otras personas sienten, saber ponerse en su lugar, sintonizar con las señales sociales que indican lo que los demás quieren o necesitan. Para llegar a conseguir dicha capacidad debemos trabajar en el aula la comunicación (verbal y no verbal) y la escucha, estableciendo una relación emocional hacia los demás que haga superar al niño su etapa egocéntrica y le posibilite a percibir las situaciones desde otro punto de vista.

- Control de las relaciones (Destreza social): que implica dirigirse a las personas, sabiendo relacionarse y entenderse con ellas. Esta relación debe focalizarse en el desarrollo de un objetivo común, en el desarrollo de la asertividad (entendida como la destreza para saber expresar de forma apropiada, directa,

Ibarrola, B y E. Delfo (2005): Sentir y Pensar: Programa de Inteligencia emocional para niños y niñas de 6 a 8 años. Madrid. Ed. SM 
abierta y honesta, sus opiniones, sentimientos, gustos y necesidades) y en el desarrollo de la solución de conflictos.

Según Begoña Ibarrola (2009)², estas cinco competencias son muy útiles para cuatro áreas fundamentales de nuestra vida:

- Propenden a nuestro bienestar psicológico, base para el desarrollo armónico y equilibrado de nuestra personalidad.

- Contribuyen a nuestra buena salud física, moderando o eliminando patrones y/o hábitos psicosomáticos dañinos o destructivos, y previniendo enfermedades producidas por desequilibrios emocionales permanentes (angustia, miedo, ansiedad, ira, irritabilidad, etc.).

- Favorecen nuestro entusiasmo y motivación. Gran parte de nuestra motivación en distintas áreas de la vida está basada en estímulos emocionales. No olvidemos que la toma de decisiones está marcada por nuestras emociones.

- Permiten un mejor desarrollo de nuestras relaciones con las personas, en el área familiar-afectiva, social y laboral-profesional. La Inteligencia Emocional significa llevar a un nivel óptimo la relación entre las personas. Las emociones determinan cómo respondemos, nos comunicamos, nos comportamos y funcionamos en la vida diaria.

\subsection{Relación entre competencia emocional y juego teatral}

Creemos que queda perfectamente justificada la importancia del tratamiento de la Competencia Emocional en Educación infantil, pero como defienden Mayer y Salovey, es necesario establecer programas de intervención específica directamente conectados con la Inteligencia Emocional, desde la escuela y la familia. Pero ¿Cuál es el mejor camino de intervención? ¿Cuáles serías las mejores estrategias metodológicas de intervención?

Nosotros aportamos una estrategia, un recurso, un medio, una metodología el juego teatral.

La dramatización utiliza como principal herramienta el propio cuerpo: sus movimientos, sus gestos, sus palabras acompañadas de entonación y comunicación no verbal, su intencionalidad, su ritmo, sus temores escondidos tras una máscara, sus sueños, sus deseos, sus necesidades.

Por otra parte, cuando participa de algunas de esas situaciones mencionadas anteriormente y lo muestra a los demás, debe tener en cuenta cómo lo recibe el receptor, cómo debe acoplar su movimiento al compañero, cómo debe esperar respuesta, cómo debe trabajar de forma colaborativa para conseguir un fin común. No es suficiente con exteriorizar, representar, ser uno mismo....sino que debe acomodarse a lo que le rodea.

IBARROLA, B. (2009):”Crecer en emociones". Madrid. S.M. 
Estamos hablando de dramatización pero podemos observar que coinciden todos los contenidos que se trabajan con los aportados por la competencia emocional. Su nexo es evidente. El teatro en el niño, concretamente el juego teatral, proyecta su energía emocional, su seguridad personal y su creatividad al expresar sus necesidades. Y del mismo modo, puede conseguir los recursos necesarios para asimilar y superar las dificultades que le impiden conseguir una comunicación real y normalizada dentro del ambiente que le rodea.

\section{Currículo y dramatización}

Cuando hablamos de Dramatización nos referimos a las enseñanzas teatrales de carácter general que tienen como finalidad la de contribuir a la formación integral del individuo por lo que su ámbito de aplicación y desarrollo sería el que corresponde en la actualidad a la Educación Infantil, Primaria y Secundaria, aunque también pueden estar presentes en otras etapas educativas relacionadas con la educación compensatoria, las necesidades educativas especiales o la educación de adultos.

Ya el Diseño Curricular Base definía la dramatización como "una forma de representación que utiliza el cuerpo, la voz y el espacio y el tiempo escénico para expresar a otros ideas, sentimientos y vivencias". En la LOE aparecen objetivos y contenidos directamente relacionados con el juego teatral.

El objetivo general de la dramatización o del teatro en el marco escolar es desarrollar la autonomía personal, la autoestima, la creatividad y la capacidad de expresión y comunicación con los demás, y esto con independencia de que haya o no haya espectáculo teatral. ${ }^{3}$

En Educación Infantil, los objetivos a los que nos referimos son los siguientes:

- Conocer su propio cuerpo y el de los otros.

- Observar y explorar su entorno.

- Adquirir autonomía personal.

- Desarrollar sus capacidades afectivas.

- Relacionarse con los demás y adquirir pautas de convivencia así como ejercitarse en la resolución pacífica de conflictos.

- Desarrollar habilidades comunicativas en diferentes lenguajes.

- Iniciarse en las habilidades que supongan movimiento, gesto y ritmo.

- Desarrollar sus capacidades afectivas.

3 Tejedo, F. (1997) La dramatización y el teatro en el currículum escolar. Pág. 51. Ponencia del curso Teatro infantil y dramatización escolar, realizado en el Vicerrectorado de Extensión Universitaria de la Universidad de Castilla- La Mancha 
- Relacionarse con los demás y adquirir pautas de convivencia así como ejercitarse en la resolución pacífica de conflictos.

- Desarrollar habilidades comunicativas en diferentes lenguajes.

- Iniciarse en las habilidades que supongan movimiento, gesto y ritmo.

Tejerina (1994) en su ponencia sobre Teatro infantil y dramatización escolar, comienza su discurso afirmando que: "Autores, animadores, profesores, padres, reivindican el derecho de los niños a participar como espectadores y actores de un teatro propio." " Es en Educación Infantil, el momento privilegiado para empezar a celebrar y estimular la buena capacidad dramática del niño. Y es en Educación Primaria y Secundaria donde esos recursos que han adquirido, pueden ser utilizados como estrategias en su proceso de aprendizaje o en su vida personal y social. A partir de la práctica de actividades de expresión corporal, los educandos pueden ir desarrollando aspectos importantes de su personalidad, individual y social.

La utilización, en el aula, de actividades dramáticas permiten que los alumnos desarrollen sus capacidades artísticas; puedan tener más confianza para expresar sus sentimientos y emociones porque hará más ágiles y seguros su imaginación, voz y movimientos; obtendrán más herramientas de comunicación y trabajarán de forma más amena objetivos y contenidos del currículum.

Este tipo de juegos o actividades contribuyen poderosamente al aspecto formativo, tanto desde el punto de vista de la integración social como del crecimiento individual. Los alumnos logran desarrollar sus potencialidades humanas, fomenta el respeto y la consideración hacia el trabajo de los demás, desarrolla la creatividad, la imaginación y la espontaneidad, la observación, la sensibilidad y la tolerancia, el pensamiento divergente y la conciencia crítica, además de potenciar la participación y el interés por las tareas colectivas. Es decir, a través del teatro podemos convertir a nuestros alumnos en competentes emocionalmente.

Pero lo realmente importante es demostrar que el teatro debe ser vivo, original y divertido. Debe convertirse en un recurso y en un fin. Debe ser una herramienta y a la vez un premio, para el alumno y su profesor.

\section{Cómo desarrollar la Inteligencia Emosional}

\subsection{A través de la lectura y representación de cuentos}

Los cuentos son un instrumento fundamental para el desarrollo de la Inteligencia Emocional $1^{5}$ :

\footnotetext{
4 Tejerina, I.: Dramatización y teatro infantil. Dimensiones psicopedagógicas y expresivas. Madrid, SIGLO XXI; pág. 9

5 Consultado en http://cuentosparacrecer.wordpress.com
} 
- Permiten al niño conocer otras vidas, que, de alguna manera, acaban haciendo suyas.

- Ayudan al niño a identificar y comprender mejor los sentimientos tanto propios como ajenos: el miedo, el dolor, la alegría, la pérdida de algo o de alguien...

- A través del cuento y las ilustraciones, pueden identificar y analizar sus propios sentimientos observando desde fuera sus propias reacciones (estrategias, cabezonería, argumentaciones...).

- Desarrollan la sensibilidad del niño para ponerse en el lugar de otro y tratar de comprenderlo.

- Ofrecen distintas estrategias para la solución de problemas.

- Sirven al niño para liberar frustraciones y ansiedades. En este sentido, los cuentos populares, como dice Bruno Bettelheim, juegan un papel catalizador de los miedos infantiles, ayudando al niño a librarse de sus propios fantasmas.

\subsection{A través de la expresión dramática y corporal}

Los juegos de expresión dramática y corporal deben ser utilizados por el profesor con la finalidad de conseguir la comunicación y aprendizaje de la utilización de su cuerpo para expresar situaciones, acciones, deseos y sentimientos, tanto reales como imaginarios. Considerando no sólo una comunicación individual, sino grupal a través de producciones colectivas como la representación de escenas, cuentos, improvisaciones, teatro de guiñol, etc.

Será necesario, por consiguiente, que juegue a representar situaciones, historias sencillas, personajes, emociones, etc., como asistir a alguna representación especialmente pensada para ellos, además de las representaciones de sus compañeros en la escuela.

Referente a la expresión corporal, consideramos que es el conjunto de técnicas que permiten adquirir el conocimiento y el dominio del cuerpo y de sus posibilidades de movimiento.

El lenguaje del cuerpo es el más directo y el más claro. Un gesto de dolor se entiende más rápidamente que si lo contamos. Si se quieren transmitir no sólo ideas, sino sobre todo sentimientos, no se puede estar inmóvil. Además el gesto es un lenguaje universal que todo el mundo comprenderá. Los mismos sentimientos en distintos países serán expresados con los mismos gestos. No necesitan traducción. (Miravalles, 1990) ${ }^{6}$

La expresión corporal es el resultado de la interrelación de factores corporales, espaciales y temporales, que pueden implicar a todo el cuerpo, a una o varias partes del mismo, que ejecuta el movimiento sobre el propio terreno o con desplazamientos,

6 Miravalles, L. (1990); “ Iniciación a 1 teatro, teoría y práctica”, Diputación Provincial, Valladolid; pág. 53 
que sigue diferentes trayectorias y que expresa un ritmo personal, un ritmo grupal y un ritmo que responde a estímulos externos.

Podemos utilizar situaciones cotidianas para educar el gesto, tales como andar, coger una flor, asearse, tomar un vaso de leche. Educando el ritmo y la expresión natural del movimiento.

Nuestra propuesta, imitando a Bossu, es que el niño/a se vea capaz de realizar bailes o movimientos de ejercicios sencillos. Planteando que lo fundamental es la expresión que lleva a la comunicación. (Bossu, 1987)7. Siendo el juego el vehículo de actuación y motivación.

\subsection{Enfoque metodológico}

El profesor debe....

- Incitar la imaginación aportando recursos que motiven la experimentación.

- Ser flexible y no autoritario con las ideas aportadas por los alumnos.

- Tratar al alumno en su individualidad pero dentro del grupo.

- Animarles a que expresen sus ideas y elogiar sus creaciones. Creando entornos estimulantes.

- Valorar y corregir sin crear desánimo.

- Utilizar el juego como medio para el desarrollo de las actividades.

- Estimular los procesos intelectuales creativos, introduciendo ejercicios de pensamiento creativo p.e.: ejercicios de asociaciones libres entre informaciones facilitadas, distinguir problemas y percibir conexiones, analizar ideas insólitas, proponer soluciones a problemas habituales, poner en práctica la inventiva en tareas lingüísticas, gráficas, combinar materiales conocidos en aplicaciones nuevas, $\ldots$

- Utilizar el pequeño grupo, la actividad individual y la actividad en gran grupo, dependiendo de los objetivos a conseguir.

- Dar importancia al proceso (clases, sesiones y actividades relacionadas con el juego teatral) y menos al producto final (representación o puesta en escena de una obra).

Los entornos deben:

- Ser lúdicos, de confianza, colaboración y respeto.

- Disponer de un espacio amplio, cómodo que ofrezca libertad de movimiento.

Bossu, H. (1987); La expresión corporal, Barcelona, Martínez Roca S. A.; pág. 107 
- Disponer de multitud de materiales (máscaras, telas, maquillajes, objetos varios, marionetas, etc).

Los padres deben:

La colaboración familia-escuela es fundamental para el alumnado ya que es el principal y primer vehículo de comunicación y recepción de las primeras emociones e indicaciones educativas para convertir al niño en un ser social. La familia debe unirse a este tipo de estrategias donde el juego y el teatro tienen un papel fundamental.

- Mantener una actitud positiva y de recompensa hacia la actividad.

- Ayudarle a resolver problemas que se le planteen debido a su precocidad y dotes creativas.

- Proporcionarle contacto con otros niños y adultos.

- Valorar y respetar sus contribuciones: ideas, productos,...

- Llevarle a oír música, ver exposiciones, ballet,...

- Desarrollar la atención, la actitud de escucha y tolerancia ante ideas nuevas

Algunas pautas metodológicas que pueden servir: (Alba, 2007):

- Se ha de partir de las vivencias, experiencias y conflictos que les suceden a los niños y a las niñas dentro del aula y fuera de ella y que dan origen a la alegría, la tristeza, la rabia, los celos, la ternura, el cariño, el miedo, etc... Se ha de aprovechar para darle un tratamiento educativo.

- Se debe permitir que expresen lo que sienten, lo exterioricen, le pongan nombre (por ejemplo, vamos a imaginar que recibimos una sorpresa....)

- Cuando sospechamos que un niño o niña somatiza problemas emocionales se debe conversar con la familia y darle o recibir pautas.

- Los juegos de brujas, monstruos, fantasmas, ayudan a exteriorizar el miedo y da paso a controlarlo.

- La expresión de emociones se ha de propiciar a través de: el cuerpo, el lenguaje oral, el dibujo, la pintura, escultura, juego, cuentos, dramatización, música, danza y escritura.

\subsection{Campos de actuación}

Los campos de actuación estarían englobados en:

8 Cita sacada del libro Alba, A. R. (2007): "Los Buenos Tratos" publicado por la Consejería de Servicios Sociales de la Rioja. El programa va dirigido a niños y niñas de Educación Infantil de La Rioja, y pretende educar para la igualdad y favorecer la prevención de conductas violentas. Para llevarlo a cabo, es importante reflexionar sobre la importancia del desarrollo emocional y la construcción de la personalidad desde el momento del nacimiento. 
- Juego dramático: Es necesario entender que hay juego dramático cuando el niño se expresa ante los demás con deleite, a través de gestos y la palabra. Lo importante es que los alumnos respondan al primer impulso y estímulo ofrecido por el profesor (Ejemplo: "Vamos andando por la calle, hace mucho frío, tenemos miedo....)

- Ejercicio dramático: A través de los ejercicios se puede desarrollar los medios de expresión, atención, concentración, sensibilidad, vocalización, respiración, etc. Deben ser sencillos y adecuados a su desarrollo madurativo. (Ejemplo: "Tomamos aire por la nariz y llenamos la tripilla, soplamos despacito, despacito hasta que quede vacía")

- Improvisaciones: Es la creación de una escena dramática donde determinados personajes dialogan de manera espontánea, como consecuencia de un estimulo determinado, por ejemplo una palabra o situación, una música, personajes, objetos, temas o narraciones. (Ejemplo: "Imaginamos que estamos en el patio y viene un niño mayor y nos quita la merienda...")

- Pantomima o mimo: Es el arte de comunicar ideas, a través de movimientos y actitudes expresivas del cuerpo. Para hacer pantomima es necesario recordar emociones: cómo hacemos cuando tenemos cólera, cuando estamos tristes, cuando estamos asustados, etc. Permite al niño expresarse adecuadamente de todo lo que siente. (Ejemplo: "Cuando pare la música nos quedamos como estatuas pero tiene que ser una estatua triste, loca, rara, enfadada....")

- Títeres: La actividad con títeres es altamente formativa, pues enriquece la creatividad, la expresividad, y ejercita la agilidad mental. Teniendo el valor añadido de contar con - el no yo-. Utilizando el muñeco para exteriorizar sus tensiones y temores.

- Danza creativa: Es la creación improvisada de movimientos y desplazamiento rítmicos, en respuesta a una motivación externa como los sonidos, o a una motivación interna, como ideas y sentimientos.

- Creación artística: utilizando distintos utensilios, herramientas o elementos para la creación de vestuarios, decorados, atrezzo, etc.

\section{Conclusiones}

Es importante reflexionar sobre la importancia del desarrollo emocional y la construcción de la personalidad desde el momento del nacimiento. En la familia es donde el niño va a descubrir sus primeras sensaciones afectivas, donde van a surgir los primeros llantos y rabietas como medio de comunicación emocional. Cuando llega a la escuela, el alumno sigue aprendiendo y busca experiencias que le influyan en su personalidad, en su manera de hacer, en su encuentro con los demás. Ese camino donde se descubre, se acepta y encuentra a los demás, debe ser acompañado por el 
docente que le enseñe, anime y le eduque no sólo en inteligencias que desarrollen habilidades y destrezas intelectuales. Pero ese camino será más lúdico y dinámico si lo pintamos de juego, de teatro, de creatividad.

Así se ha hecho en una experiencia (que por falta de espacio ya contaremos en otra ocasión) llevada a cabo en un centro de la ciudad de Toledo, donde se ha podido descubrir el ilimitado recurso y estrategia metodológica que puede llegar a ser la utilización del juego teatral dentro de un aula de Infantil. Donde se ha descubierto la conexión entre competencia emocional, creatividad y juego teatral. Los resultados han sido muy positivos y valorados por los distintos integrantes: alumnos, docentes y familias. Incluso los alumnos con necesidades educativas especiales han encontrado una herramienta útil para su vida personal que le permite encontrar "otras" vías de comunicación. Los docentes están satisfechos por los logros conseguidos e incluso denotan su extrapolación a otras áreas de conocimiento o competencias curriculares. Los compañeros han aprendido a conocer, respetar y disfrutar de todos los integrantes de su grupo. Y por último, los padres ven a sus hijos más contentos, sociables y receptivos.

Pero no debemos dar el trabajo por terminado, sino considerar que se ha abierto una importante puerta a un método diferente, atractivo, creativo e innovador. El único requisito para "jugar todos" aprendiendo, es querer explorar y ser respetuoso con los demás, y el juego teatral nos ofrece una alternativa para conseguirlo.

El aprendizaje ideal se desarrolla con la cabeza, el corazón y las manos. (H. Pestalozzi)

\section{Bibliografía}

ALBA, A.R. (2007). La magia de los buenos tratos. La Rioja: Sidecar

BAENA, G. (2005). Como desarrollar la Inteligencia emocional. Guía para padres y maestros. Sevilla: Ed. Trillas

CAÑAS, J. (1993). Actuando, guía didáctica para jugar contigo al teatro. Barcelona: Octaedro.

CAÑAS, J. (1999). Actuar para ser. Tres experiencias de taller-teatro en la escuela y una guía-práctica. Granada: Ediciones mágina/octaedro, s.l.

CAÑAS, J. (2001). La educación artística, clave para el desarrollo de la Creatividad. Madrid: Ministerio de Educación, Cultura y Deporte - Secretaría General de Educación y Formación Profesional -

CERVERA, J. (1985). Cómo practicar la dramatización con niños de 4 a 14 años. Madrid: Cincel-Kapelusz.

CERVERA, G. (1982). Teatro y educación. Barcelona: Edebé.

GENTO PALACIOS, S. (2004). Guía Práctica para la Investigación en Educación. Madrid: Sanz y Torres.

GOLEMAN, D. (1996). Inteligencia Emocional. Barcelona: Kairós. 
GOLEMAN, D. (2005). El espíritu creativo. Argentina: Ed. B. Aires

BOSSU, H. y CHALAGUIER, C. (1987). La expresión corporal. Método y práctica. Barcelona: Martínez Roca.

IBARROLA, B. (2005). Cuentos para sentir. Educar las emociones. Madrid: Ed. S.M.

IBARROLA, B. (2009). Crecer en emociones. Madrid: S.M.

LOGAN, L.M. (1998). Estrategias para una enseñanza creativa. Barcelona: OikosTau.

MOTOS, T. (2007). Prácticas de dramatización. Madrid: Ñaque Editorial.

REVISTA DIGITAL "PRACTICA DOCENTE”. No3 (Julio/septiembre. 2006). CEP de Granada. ISSN: 1885-6667. DL: GR-2475/05

MENENDEZ PONTE, M. (1997) "El desarrollo de la Creatividad y de la inteligencia Emocional del niño a través de la lectura". Ponencia en la Universidad de Córdoba.

\section{La autora}

Purificación Cruz Cruz, Diplomada en Magisterio por Educación Infantil. Licenciada en Psicopedagogía. Doctorando en Educación Infantil y Familiar. Tesis en desarrollo: "El juego teatral como herramienta para el tratamiento educativo y psicopedagógico de algunas situaciones y necesidades educativas en la infancia". Maestra en el Colegio Nuestra Señora de los Infantes desde hace 25 años. Profesora Asociada de la Facultad de Educación de Castilla La Mancha. Toledo. Directora del grupo de teatro infantil "Colorín". Monitora teatral. Participante en numerosos congresos y encuentros sobre Inteligencia y Competencia Emocional. 